\title{
GREAT BLACK-BACKED GULL (Larus marinus)
}

NICK SAUNDERS, Saskatoon, SK
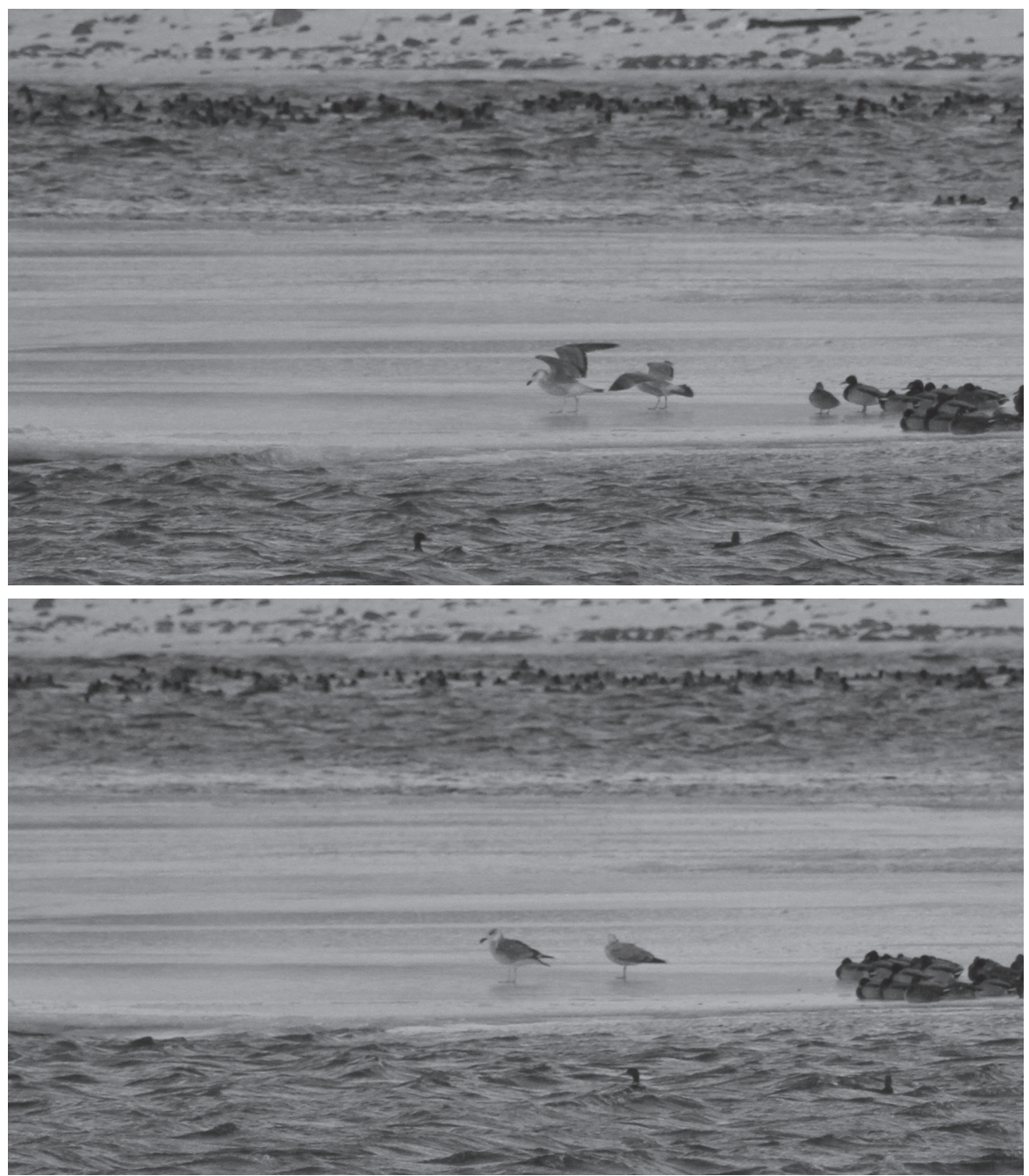

-Nick Saunders

This photo was taken of an unusual bird that was noticed and identified during the 2013 Christmas Bird Count. "New Species: A Great Blackbacked Gull at Gardiner Dam on 16 December is the first record on the $\mathrm{CBC}$ and only the ninth provincial record."

1. Smith AR (2013) $72^{\text {nd }}$ Annual Saskatchewan Christmas Bird Count - 2013. Blue Jay 72(1) pp2 -27. 